\title{
The Relevance of Nasal Provocation Testing in Children with Nonallergic Rhinitis
}

\author{
Handan Duman Ilknur Bostanci Serap Ozmen Mahmut Dogru \\ Department of Pediatric Immunology and Allergy, Sami Ulus Maternity and Children Research and Training \\ Hospital, Ankara, Turkey
}

\section{Key Words}

Nasal provocation test $\cdot$ Children $\cdot$ Nonallergic rhinitis

\begin{abstract}
Background: It is important to understand that allergic rhinitis, whether seasonal or perennial, may be difficult to distinguish clinically from the nonallergic forms of rhinitis. $\mathbf{O b}$ jective: This study aimed to investigate the presence of local allergic rhinitis (LAR) in children who have allergic rhinitis symptoms in the absence of skin test positivity and specific IgE by performing a nasal provocation test (NPT). Methods: Our study followed a case-controlled, prospective design. Twenty-eight patients and 30 healthy children were included in the study in a pollen-free season. The NPTs with a grass mix, Dermatophagoides pteronyssinus (DP) and D. farinae (DF) allergens were performed with an interval of 1 week. The total symptom score and visual analog scale, nasal eosinophilia and pulmonary function tests were evaluated before and after each NPT. The change to nasal flow and resistance was recorded by anterior rhinomanometry. Results: The symptom frequencies before the NPTs were as follows: nasal congestion 100\%; itching $82.1 \%$; rhinorrhea $75 \%$ and sneezing $71.4 \%$. The NPT was positive in $7(25 \%)$ patients. In the NPT-positive group there was a statistically significant
\end{abstract}

decrease in nasal flow at the concentrations of 10 and 100 IR/ml for DF ( $p=0.026, p=0.031$, respectively). In the NPTpositive group total nasal resistance for DP was increased at the concentrations of 0.1 and $10 \mathrm{IR} / \mathrm{ml}$, and for DF at 10 and $100 \mathrm{IR} / \mathrm{ml}(\mathrm{p}=0.049, \mathrm{p}=0.041, \mathrm{p}=0.022, \mathrm{p}=0.035$, respectively). Conclusions: We emphasize that the diagnosis of LAR should be taken into consideration by pediatricians and pediatric allergy specialists.

(c) 2016 S. Karger AG, Basel

\section{Introduction}

Rhinitis is classified into two categories - either allergic or nonallergic. In recent years, local allergic rhinitis (LAR) has been defined as a new phenotype of allergic rhinitis characterized by nasal symptoms of allergic rhinitis in the absence of sensitivity in a skin prick test (SPT) or serum-specific IgE, a positive response to a specific nasal provocation test (NPT) and the presence of a Th2 immune inflammatory response in the nasal mucosa with

This study was presented at the P-684, EAACI-WAO World Allergy and Asthma Congress, held in Milan, Italy, June 22-26, 2013; poster session 17 - Interventions in Pediatric Allergy: Clinical Outcomes.

\section{KARGER}

E-Mail karger@karger.com

www.karger.com/iaa
(C) 2016 S. Karger AG, Basel

$1018-2438 / 16 / 1702-0115 \$ 39.50 / 0$
Correspondence to: Prof. Dr. Ilknur Bostanci

Department of Pediatric Immunology and Allergy

Sami Ulus Maternity and Children Research and Training Hospital

Babur Caddesi, 44, Telsizler-Altindag, TR-06080 Ankara (Turkey)

E-Mail ilknurbirol@hotmail.com 
local production of specific IgE [1-5]. Powe et al. [6] enounced 'entopy' by describing the activation of a Th2 immune response in the nasal mucosa of nonallergic rhinitis patients. In European studies it has been estimated that LAR may affect $47 \%$ of adult patients with perennial symptoms and $62.5 \%$ with seasonal symptoms $[2,7]$. There were previously no data about the prevalence of LAR in children.

This study aimed to investigate the presence of LAR in children who have allergic rhinitis symptoms in the absence of skin test positivity and specific IgE by performing an NPT with grass mix, Dermatophagoides pteronyssinus (DP) and D. farinae (DF) allergens.

\section{Methods}

In our study we enrolled a total of 28 children with nonallergic rhinitis and 30 healthy nonatopic children as the control group. Both groups were studied out of the pollen season and when the patients were symptom free or with only mild symptoms. According to ARIA (Allergic Rhinitis and Its Impact on Asthma), allergic rhinitis is suggested by the presence of 2 or more of the following symptoms for $>1 \mathrm{~h}$ on most days: watery anterior rhinorrhea, sneezing - especially paroxysmal, nasal obstruction, and nasal pruritus with or without conjunctivitis over a 2 -year period. All the children's parents gave their informed consent and the study was approved by the local ethics committee.

\section{Inclusion Criteria for the Patient Group}

The inclusion criteria for the patient group were as follows: (1) Negative SPT or serum-specific IgE for DP, DF and the grass mix; (2) being over 5 years of age in order to cooperate in the NPT; (3) no evidence of vasomotor rhinitis (rhinitis induced by physical or chemical factors), chronic rhinosinusitis with or without nasal polyps, structural defects (such as septum perforation or septum deviation), nonallergic rhinitis with eosinophilic syndrome or rhinitis medicamentosa; (4) no respiratory infection during the previous 4 weeks; (5) no treatment with nasal or systemic corticosteroids during the previous 4 weeks, and (6) no treatment with antihistamines or nasal vasoconstrictors during the previous 2 weeks.

\section{Inclusion Criteria for the Control Group}

The inclusion criteria for the control group were as follows: (1) no symptoms of rhinitis; (2) a negative SPT, and (3) general good health.

The patient age, gender and family history of atopy, the duration and properties of rhinitis (frequency: intermittent/persistent; severity: mild/moderate/severe; timing: perennial/seasonal) [8], and the presence of asthma and conjunctivitis were determined. No patient in the study groups had adenoidal hypertrophy. The complete blood count, peripheral blood smear (for eosinophilia), serum total IgE and specific IgE for house dust mite and grass (UniCAP; Phadia, Uppsala, Sweden) were evaluated. The cutoff value for serum IgE was $0.35 \mathrm{kU} / \mathrm{l}$. The severity of symptoms of nasal secretion, irritation (sneezing) and extranasal symptoms, such as tearing/itching, conjunctivitis/chemosis, urticaria and coughing/dyspnea, were evaluated according to the Gosepath symptom scoring system before and during the NPT [9]. The scores for each symptom were calculated and named as the total symptom score (TSS). The patients used a visual analog scale (VAS) of $10 \mathrm{~cm}$ to record symptoms of obstruction, rhinorrhea, itching and sneezing. The TSS and VAS of patients were recorded before and after each NPT.

\section{Skin Prick Testing}

SPT was performed with house dust mite (D. farinae, D. pteronyssinus), 5 mixed grass pollens (Dactylis glomerata, Anthoxantum odoratum, Loilum perenne, Festuca elatior, Phleum pratense), a cereal mix, tree mix, cockroaches, molds (Alternaria alternata, Aspergillus), and cat and dog epithelia (Stallergenes, Antony, France).

\section{Nasal Provocation Test}

The NPT was performed in all patients and healthy controls. The NPT was carried out with anterior rhinomanometry after the patients had waited for $30 \mathrm{~min}$ at a room temperature of $20-22^{\circ} \mathrm{C}$ in the morning (ZAN 100 USB Rhinomanometry; Longmont, Colo., USA). Firstly, a saline nasal challenge was performed to exclude nasal hyperreactivity. If negative to saline nasal challenge, a nasal smear was performed with the help of a cotton applicator from a bilateral lower turbinate. After air drying, they were stained with hematoxylin and eosin. Then the nasal challenges were performed at weekly intervals using the freshly reconstituted allergens [mix of 5 grass pollens (D. glomerata, A. odoratum, L. perenne, F. elatior, $P$. pratense), DP and DF] titrated in an index of reactivity of 100 (IR; freeze-dried extract, 100 IR/ml, Alyostal NPT; Stallergenes). The allergen dose of $100 \mu \mathrm{l}$ per nostril using a metered spray aerosol was administered in increasing concentrations (0.1, $1,10$ and $100 \mathrm{IR} / \mathrm{ml})$. The nasal response was measured $15 \mathrm{~min}$ after each allergen dose by anterior rhinomanometry. A positive NPT was considered to be a $40 \%$ decrease in nasal flow at $150 \mathrm{~Pa}$ compared with the baseline test or a $20 \%$ decrease in nasal flow with a TSS greater than 2 according to Gosepath symptom scoring. a nasal smear was repeated $1 \mathrm{~h}$ after the NPT. In addition, pulmonary function tests were performed before and after each NPT.

\section{Data Analysis}

All statistical analyses were performed with SPSS for Windows 17.0 (SPSS Inc., Chicago, Ill., USA). Descriptive statistics were expressed as the mean \pm standard deviation (SD), median, frequency and percent. The $t$ test was used between two independent groups with a normal distribution, and the Mann-Whitney U test for an abnormal distribution. The Wilcoxon signed-ranks test or Friedman test was used to compare data at different times within groups with abnormal distributions and the $t$ test was used for normal distributions. Correlations were analyzed using Spearman's test.

\section{Results}

Twenty-eight patients with nonallergic rhinitis and 30 healthy control subjects were included in our study. The demographic and clinical data of the groups are presented in table 1 . Table 2 shows the laboratory data of the groups. A total of 1,200 patients with rhinitis were admit- 
Table 1. Demographic and clinical data of the group

\begin{tabular}{lccc}
\hline & $\begin{array}{c}\text { Patients } \\
(\mathrm{n}=28)\end{array}$ & $\begin{array}{l}\text { Controls } \\
(\mathrm{n}=30)\end{array}$ & $\mathrm{p}$ \\
\hline Age, years & & & $0.60^{\mathrm{a}}$ \\
$\quad$ Mean \pm SD & $10.0 \pm 2.9$ & $10.4 \pm 2.8$ & \\
$\quad$ Range & $5-16$ & $6-17$ & \\
$\quad$ Median & 10 & 10 & \\
Male gender, $\mathrm{n}$ & $17(60.8)$ & $20(65)$ & $0.63^{\mathrm{b}}$ \\
Asthma comorbidity, $\mathrm{n}$ & $10(35.7)$ & 0 & $0.00^{\mathrm{b}}$ \\
Family history of atopy, $\mathrm{n}$ & $10(35.7)$ & $4(13.3)$ & $0.04^{\mathrm{b}}$ \\
\hline
\end{tabular}

Values in parentheses are percentages. ${ }^{\mathrm{a}} \mathrm{t}$ test. ${ }^{\mathrm{b}} \chi^{2}$ test.
Table 2. Laboratory data of the group

\begin{tabular}{|c|c|c|c|}
\hline & $\begin{array}{l}\text { Patients } \\
(\mathrm{n}=28)\end{array}$ & $\begin{array}{l}\text { Controls } \\
(\mathrm{n}=30)\end{array}$ & $\mathrm{p}$ \\
\hline Eosinophilia, \% & & & $0.00^{\mathrm{a}}$ \\
\hline Mean \pm SD & $2.86 \pm 1.36$ & $1.73 \pm 0.78$ & \\
\hline Range & $1-6$ & $1-4$ & \\
\hline Median & 3 & 2 & \\
\hline Total serum IgE (log), IU/ml & & & $0.23^{\mathrm{b}}$ \\
\hline Mean \pm SD & $1.39 \pm 0.65$ & $1.62 \pm 0.65$ & \\
\hline Range & $0.30-2.50$ & $0.70-2.94$ & \\
\hline Median & 1.23 & 1.51 & \\
\hline
\end{tabular}

significant correlation between the TSS of the NPT-positive patients and VAS before NPT with the grass mix and $\mathrm{DP}$, and before and after NPT with DF $(\mathrm{r}=0.98, \mathrm{p}<0.001$; $r=0.90, p=0.005 ; r=0.97, p<0.001 ; r=0.90, p=0.005$, respectively). In the nonallergic rhinitis group, nasal eosinophilia before and after NPT with DP and DF were significantly different $(1.6 \pm 1.5,2.2 \pm 1.9$, and $1.5 \pm 1.4$, $2.2 \pm 2.2$, respectively; $\mathrm{p}=0.020, \mathrm{p}=0.061$ ). The nasal eosinophilia before and after NPT with the grass mix was not different $(\mathrm{p}=0.047)$.

The nasal flow rate was significantly reduced in the NPT-positive group with DF at concentrations of 10 and $100 \mathrm{IR} / \mathrm{ml}(\mathrm{p}=0.026, \mathrm{p}=0.031$, respectively). The nasal resistance was significantly increased with DP at concentrations of 0.1 and $10 \mathrm{IR} / \mathrm{ml}$, and with DF at doses of 10 and $100 \mathrm{IR} / \mathrm{ml}(\mathrm{p}=0.049, \mathrm{p}=0.041, \mathrm{p}=0.022, \mathrm{p}=0.035$, respectively). The nasal flows were decreased with the grass mix at $0.1 \mathrm{IR} / \mathrm{ml}$ in 2 patients $(\mathrm{p}=0.047, \mathrm{p}=0.047)$. One of our patients had sneezing and flushing and a $40 \%$ decrement in nasal flow $1 \mathrm{~h}$ after NPT, and his test was accepted as positive.

There were no complications during NPT, such as coughing, asthma attack, dyspnea or eye symptoms. Only 1 patient had a headache at $4 \mathrm{~h}$ after NPT with DP.

\section{Discussion}

In recent years it has been reported that some patients with nonallergic rhinitis have local production of specific IgE antibodies in their nasal mucosa. These patients have no serum-specific IgE, have negative skin and intradermal tests, and are categorized as LAR [2, 3, 6, 9]. We believe that this is the first and only study of LAR in child- 
Table 3. The clinical and laboratory results of the patient group

\begin{tabular}{|c|c|c|c|}
\hline & NPT positive $(\mathrm{n}=7)$ & NPT negative $(\mathrm{n}=21)$ & $\mathrm{p}$ \\
\hline Age, years & & & $0.97^{\mathrm{a}}$ \\
\hline Mean \pm SD & $10.00 \pm 2.16$ & $10.00 \pm 3.17$ & \\
\hline Range & $6-13$ & $5-16$ & \\
\hline Median & 10 & 10 & \\
\hline Male gender, $\mathrm{n}$ & $5(71.4)$ & $12(57.1)$ & $0.67^{\mathrm{b}}$ \\
\hline Asthma comorbidity, $\mathrm{n}$ & $2(28.6)$ & $8(38.1)$ & $1.00^{\mathrm{b}}$ \\
\hline Family history of atopy, $\mathrm{n}$ & $1(14.3)$ & $9(42.9$ & $0.36^{\mathrm{b}}$ \\
\hline ARIA classification, $\mathrm{n}$ & & & $0.75^{\mathrm{b}}$ \\
\hline Persistent moderate/severe & $4(57.1)$ & $9(42.9)$ & \\
\hline Persistent mild & $1(14.3)$ & $3(14.3)$ & \\
\hline Intermittent moderate/severe & $2(28.6)$ & $6(28.6)$ & \\
\hline Intermittent mild & $0(0)$ & $3(14.3)$ & \\
\hline Rhinitis type, $\mathrm{n}$ & & & $0.42^{\mathrm{b}}$ \\
\hline Seasonal & $4(57.1$ & $8(38.1$ & \\
\hline Perennial & $3(42.9)$ & $13(61.9)$ & \\
\hline Rhinitis duration, years & & & $0.72^{\mathrm{c}}$ \\
\hline Mean \pm SD & $3.86 \pm 2.03$ & $3.52 \pm 2.01$ & \\
\hline Range & $2-6$ & $2-10$ & \\
\hline Median & 3 & 3 & \\
\hline Eosinophilia, \% & & & $0.14^{\mathrm{c}}$ \\
\hline Mean \pm SD & $3.29 \pm 0.75$ & $2.71 \pm 1.52$ & \\
\hline Range & $2-4$ & $1-6$ & \\
\hline Median & 3 & 3 & \\
\hline Total serum IgE (log), IU/ml & & & $0.34^{\mathrm{a}}$ \\
\hline Mean \pm SD & $1.64 \pm 0.86$ & $1.32 \pm 0.59$ & \\
\hline Range & $0.3-2.5$ & $0.7-2.5$ & \\
\hline Median & 1.71 & 1.20 & \\
\hline
\end{tabular}

Table 4. NPT allergens and doses

\begin{tabular}{lrlllllll}
\hline $\begin{array}{l}\text { Pa- } \\
\text { tient } \\
\text { No. }\end{array}$ & $\begin{array}{l}\text { Age, } \\
\text { years }\end{array}$ & Gender & $\begin{array}{l}\text { Asthma } \\
\text { comorbi- } \\
\text { dity }\end{array}$ & $\begin{array}{l}\text { Years } \\
\text { of } \\
\text { rhinitis }\end{array}$ & $\begin{array}{l}\text { Seasonal/ } \\
\text { persistent }\end{array}$ & Allergen & $\begin{array}{l}\text { Dose at } \\
\text { positivity, } \\
\text { IR/ml }\end{array}$ & ARIA \\
\hline 1 & 6 & Male & Yes & 2 & Seasonal & Grass mix & 10 & Persistent moderate/severe \\
2 & 13 & Female & No & 3 & Seasonal & Grass mix & 10 & Intermittent moderate/severe \\
3 & 10 & Male & Yes & 6 & Persistent & DP & 100 & Persistent \\
4 & 9 & Male & No & 2 & Seasonal & DP & 100 & Persistent moderate/severe \\
5 & 10 & Male & No & 6 & Seasonal & DP & 0.1 & Persistent mild \\
6 & 11 & Male & No & 2 & Seasonal & DF & 10 & Intermittent moderate/severe \\
7 & 11 & Female & No & 6 & Persistent & DF & 100 & Persistent moderate/severe \\
\hline
\end{tabular}

hood as we could not find any such study in the English literature up to August 2013. A total of 1,200 patients with rhinitis were admitted to our pediatric allergy clinic and 28 of them were enrolled to the study. There were no data about the prevalence of idiopathic rhinitis in children, but it is estimated that the onset of LAR started in childhood in approximately more than one third of the patients [10].

Seven $(25 \%)$ of the patients had a positive NPT: 2 with the grass mix, 3 with DP and 2 with DF. There was no positive response in the control group. This study showed 
Table 5. Symptoms in the patient group

\begin{tabular}{lccc}
\hline & $\begin{array}{c}\text { NPT positive } \\
(\mathrm{n}=7)\end{array}$ & $\begin{array}{c}\text { NPT negative } \\
(\mathrm{n}=21)\end{array}$ & $\mathrm{p}$ \\
\hline Nasal obstruction, $\mathrm{n}$ & $7(100)$ & $21(100)$ & \\
$\quad$ Mild & 0 & $2(9.5)$ & \\
Moderate & $3(42.9)$ & $6(28.6)$ & \\
Severe & $4(57.1)$ & $13(61.9)$ & \\
\hline Nasal rhinorrhea, $\mathrm{n}$ & 6 & $15(71.5)$ & $0.63^{\mathrm{a}}$ \\
Mild & $2(28.6)$ & $9(42.9)$ & \\
Moderate & $3(42.9)$ & $3(14.3)$ & \\
Severe & $1(14.3)$ & $3(14.3)$ & \\
\hline Itching, $\mathrm{n}$ & 6 & $17(81.0)$ & $1.00^{\mathrm{a}}$ \\
Mild & $3(42.9)$ & $6(28.6)$ & \\
Moderate & $2(28.6)$ & $8(38.1)$ & \\
Severe & $1(14.3)$ & $3(14.3)$ & \\
\hline Sneezing, $\mathrm{n}$ & $4(57.2)$ & $16(76.2)$ & $0.37^{\mathrm{b}}$ \\
Mild & $1(14.3)$ & $5(23.8)$ & \\
Moderate & $2(28.6)$ & $10(47.6)$ & \\
Severe & $1(14.3)$ & $1(4.8)$ & \\
\hline TSS & & & \\
Mean \pm SD & $6.71 \pm 1.97$ & $6.48 \pm 1.83$ & $0.74^{\mathrm{b}}$ \\
Range & $3-9$ & $3-9$ & \\
Median & 7 & 7 & \\
\hline
\end{tabular}

Values in parentheses are percentages. ${ }^{a}$ Spearman's test. ${ }^{b}$ t-test.

that LAR could be identified in children as in adults. Rondón et al. [3] detected NPT positivity as 54\% among 50 adult patients with nonallergic persistent rhinitis and $22 \%$ had positive specific IgE in their nasal lavage. Carney et al. [7], using different allergens (DP, DF, cat-dog epithelia, and a grass-cereal mix), recorded a positive NPT in $62 \%$ of a group of 23 adult patients with idiopathic rhinitis. In our study, we found a positive NPT for the grass mix in 2 of the 12 patients with seasonal idiopathic rhinitis $(16.6 \%)$, and 5 of 16 patients $(31.2 \%)$ with perennial rhinitis had positive NPTs with DP or DF. Our patients were young and we believed that sensitization had begun recently. Thus, we found a low percentage of NPT positivity. It is not known if patients with a positive NPT will grow up with future atopy. As our study was a cross-sectional study, longitudinal studies are also needed.

Considering total serum IgE and nasal eosinophilia revealed no differences between the groups. Serum eosinophil levels were higher in the patient group but the average level of eosinophils was under $4 \%$. In the literature it was noticed that mast cells, eosinophils, IgE and T cells were higher in the nasal mucosa of patients with LAR [11].

NPT in Children with Nonallergic Rhinitis
Rondón et al. [4] evaluated tryptase, eosinophilic cationic protein (ECP) and specific IgE levels in the nasal secretions of patients with a positive NPT for grass pollen. They found that $40 \%$ of the patients had an immediate response and $70 \%$ had a late response. There was a strong correlation between tryptase level and itching and sneezing, and also a positive correlation for nasal ECP and nasal obstruction. In our study, we were only able to consider the nasal eosinophils in nasal mucosa and we found no difference between the positive and negative NPT groups for eosinophils. Evaluating nasal lavage fluids by flow-cytometric analysis and the determination of specific IgE, ECP and tryptase levels could be more informative.

It is known that asthma and allergic rhinitis have similar immunopathologic mechanisms; $38 \%$ of patients with allergic rhinitis also have asthma and $78 \%$ of patients with asthma have allergic rhinitis [12]. In our study $35.7 \%$ of the patients had asthma comorbidity, but we found no difference between the NPT-positive and negative groups and also no difference for pulmonary function tests. Only 1 patient with a positive NPT for DF had a $10 \%$ decrease in $\mathrm{FEV}_{1}$ during the test. Marcucci et al. [13] performed NPTs in asthmatic patients with monosensitization to DP and 14 patients with rhinitis. They found a decrement in the $\mathrm{FEV}_{1}$ level in 3 patients with asthma but no decrement in patients with rhinitis. Similar to our findings, Hervás et al. [14] reported a decrement in only 1 patient among 125 children.

According to the ARIA classification, 4 of our patients with a positive NPT had persistent moderate/severe symptoms, 2 had intermittent moderate/severe symptoms and 1 had persistent mild symptoms. Similar to our findings, Rondón et al. [15] reported that the patients with a positive NPT had persistent moderate/severe symptoms. In addition, we found no difference between the positive and negative NPT groups for symptoms in terms of seasonal or perennial rhinitis. Consistent with the literature, we found no difference for the duration of rhinitis.

The most common symptoms in our patients were nasal obstruction (100\%) followed by itching (82.1\%). There were no differences in the symptoms between the positive and negative NPT groups. Rondón et al. [2] reported that posterior nasal secretion was the most common symptom in patients with idiopathic rhinitis and sneezing was the most frequent among patients with allergic rhinitis.

We found a positive correlation between TSS and VAS before NPT with DP, DF and the grass mix. Reflecting our findings, Jáuregui et al. [16] reported a positive correla-

Int Arch Allergy Immunol 2016;170:115-121 119 
tion for TSS and median VAS at the age of 6-12 years in 1,275 children with allergic rhinitis. We can say that children are able to use a VAS in the same way as adults.

Anterior rhinomanometry, acoustic rhinometry, nasal inspiratory peak value, and optic rhinometry can be used for objective evaluation of NPTs. All methods have advantages and disadvantages [17]. There was no difference for basal nasal flow and basal nasal resistance in our study with anterior rhinomanometry for the positive and negative NPT groups. We found an increase in total nasal resistance during the tests with DP and DF, and a decrease in nasal flow with the DF test. There was a minimum $40 \%$ decrease in nasal flow during the tests in all NPT-positive patients, but we could not report a significant statistical difference for all test values. All patients had sneezing and nasal discharge during the positive tests. We used the symptom score that was developed by Gosepath et al. [8]. Nasal obstruction, nasal discharge, sneezing and the other findings (eye secretion, conjunctivitis, urticaria, dyspnea and cough) were evaluated. No other symptoms developed during the tests in our study. Only 1 patient had a headache after the test and no other complication was seen. Baroody et al. [18] reported sinus inflammation during NPT in patients with allergic rhinitis. Ache in our patients was localized in the right frontal sinus and it lasted for 24-36 h, and might have been associated with sinus inflammation.

It is interesting to consider whether those patients with LAR will develop systemic atopy in the future. Rondón et al. [19] reevaluated their patients 3 years after the first evaluation and found that $24 \%$ of the patients developed positivity in skin tests and they emphasized that those patients with LAR would have allergic rhinitis in the following years. We plan to follow up our patients for developing systemic allergy. On the other hand, there was a doubt about applying immunotherapy in these patients. Rondón et al. [15] applied immunotherapy to 10 of their 20 patients with LAR and they reported that at the sixth month of therapy the NPT of 3 patients had become negative whilst 4 patients developed a positive pollen sensitization in their SPTs and all patients' symptoms were under control.

One of the limitations of this study was the small number of patients, which may explain the lack of statistically significant clinical differences. Therefore, there is a need for further comprehensive studies [20]. Another limitation was that most of our patients came from other cities than Ankara, meaning we were unable to reevaluate them for delayed symptoms and laboratory parameters such as nasal eosinophilia, pulmonary function tests and rhinomanometry.

\section{Conclusion}

We recorded a positive NPT in 7 out of 28 nonallergic rhinitis patients (25\%), in whom LAR was diagnosed. We have shown that LAR could be diagnosed during childhood. Anterior rhinomanometry can be useful in assessing the response to NPT in children over 5 years of age when diagnosing LAR. Nasal provocation testing is a safe, noninvasive, well-tolerated, cheap and repeatable diagnostic test for the identification of LAR in this age group for those with a negative SPT and no detectable serumspecific IgE. This study should encourage pediatricians and pediatric allergy physicians to be aware of LAR in children. The long-term follow-up of these children for the development of atopy may be important.

\section{Acknowledgement}

We would like to thank Soner Sahin for his technical assistance in performing nasal provocation tests.

\section{Disclosure Statement}

The authors have no conflicts of interest. This study was approved by the local ethics committee.

\section{References}

1 Huggins KG, Brostoff J: Local production of specific IgE antibodies in allergic-rhinitis patients with negative skin tests. Lancet 1975;2: 148-150

2 Rondón C, Doña I, López S, Campo P, Romero JJ, Torres MJ, et al: Seasonal idiopathic rhinitis with local inflammatory response and specific IgE in absence of systemic response. Allergy 2008;63:1352-1358.
3 Rondón C, Doña I, López S, Campo P, Romero JJ, Torres MJ, et al: Local IgE production and positive nasal provocation test in patients with persistent nonallergic rhinitis. J Allergy Clin Immunol 2007;119:899-905.

4 Rondón C, Fernández J, López S, Campo P, Doña I, Torres MJ, et al: Nasal inflammatory mediators and specific-IgE production after nasal challenge with grass in local allergic rhinitis J Allergy Clin Immunol 2009;124:1005-1011. 
5 López S, Rondón C, Torres MJ, Campo P, Canto G, Fernandez R, et al: Immediate and dual response to nasal challenge with Dermatophagoides pteronyssinus in local allergic rhinitis. Clin Exp Allergy 2010;40:1007-1014.

6 Powe DG, Jagger C, Kleinjan A, Carney AS, Jenkins D, Jones NS: 'Entopy': localised mucosal allergic disease in the absence of systemic responses for atopy. Clin Exp Allergy 2003; 33:1-6.

7 Carney AS, Powe DG, Huskisson RS, Jones NS: Atypical nasal challenges in patients with idiopathic rhinitis: more evidence for the existence of allergy in the absence of atopy? Clin Exp Allergy 2002;32:1436-1440.

8 Gosepath J, Amedee RG, Mann WJ: Nasal provocation testing as an international standard for evaluation of allergic and nonallergic rhinitis. Laryngoscope 2005;115:512-516.

9 Rondón C, Fernandez J, Canto G, Blanca M: Local allergic rhinitis: concept, clinical manifestations, and diagnostic approach. J Investig Allergol Clin Immunol 2010;20:364-371.
10 Rondón C, Campo P, Galindo L, BlancaLópez N, Cassinello MS, Rodriguez-Bada JL, et al: Prevalence and clinical relevance of local allergic rhinitis. Allergy 2012;67:1282-1288.

11 Powe DG, Huskisson RS, Carney AS, Jenkins D, McEuen AR, Walls AF, et al: Mucosal Tcell phenotypes in persistent atopic and nonatopic rhinitis show an association with mast cells. Allergy 2004;59:204-212.

12 Casale TB, Dykewicz MS: Clinical implications of the allergic rhinitis-asthma link. Am J Med Sci 2004;327:127-138.

13 Marcucci F, Passalacqua G, Canonica GW, Frati F, Salvatori S, Di cara G, et al: Lower airway inflammation before and after house dust mite nasal challenge: an age and allergen exposure-related phenomenon. Respir Med 2007;101:1600-1608.

14 Hervás D, Rodriguez R, Garde J: Role of aeroallergen nasal challenge in asthmatic children. Allergol Immunopathol 2011;39:17-22.

15 Rondón C, Blanca-López N, Aranda A, Herrera R, Rodriguez-Bada JL, Canto G, et al: Local allergic rhinitis: allergen tolerance and immunologic changes after preseasonal immunotherapy with grass pollen. J Allergy Clin Immunol 2011;127:1069-1071.
16 Jáuregui I, Dávila I, Sastre J, Bartra J, del Cuvillo A, Ferrer M, et al: Validation of ARIA (Allergic Rhinitis and its Impact on Asthma) classification in a pediatric population: the PEDRIAL study. Pediatr Allergy Immunol 2011;22:388-392.

17 Dordal MT, Lluch-Bernal M, Sánchez MC, Rondón C, Navarro A, Montoro J, et al: Allergen-specific nasal provocation testing: review by the rhinoconjunctivitis committee of the Spanish Society of Allergy and Clinical Immunology. J Investig Allergol Clin Immunol 2011;21:1-12.

18 Baroody FM, Mucha SM, Detineo M, Naclerio RM: Nasal challenge with allergen leads to maxillary sinus inflammation. J Allergy Clin Immunol 2008;12:1126-1132.

19 Rondón C, Doña I, Torres MJ, Campo P, Blanca M: Evolution of patients with nonallergic rhinitis supports conversion to allergic rhinitis. J Allergy Clin Immunol 2009;123: 1098-1102.

20 Rondón C, Campo P, Blanca-López N, Torres MJ, Blanca M: More research is needed for local allergic rhinitis. Int Arch Allergy Immunol 2015;167:99-100. 